\title{
Pharmacognostic Standardisation and Phytochemical Evaluation on the Seeds of Two Vitis Vinefera L. Varieties Grown in Kashmir Valley, India
}

\author{
Javaid Ashraf Nowshehri' ${ }^{1}$ Zulfiqar Ali Bhat ${ }^{1 *}$, Mohammad Yaseen Shah ${ }^{1}$ \\ Department of Pharmaceutical Sciences, University of Kashmir, Srinagar, Jammu and Kashmir, INDIA.
}

\begin{abstract}
Introduction: Grape (Vitis vinifera L.) is one of the largest fruit crop widely grown throughout the world and their seeds are considered a relevant source of polyphenol compounds. Objective: To carry out phytochemical and pharmacognostic evaluation of the seeds of Vitis vinefera L. Var sahibi and hussaini, family vitiaceae as per WHO guidelines. Materials and Methods: In present investigation, the detailed pharmacognostic studies were carried out in terms of organoleptic properties, macroscopical, microscopical characters, physicochemical parameters, preliminary phytochemical screening for major groups of compounds and other WHO recommended parameters for standardization of the seeds of Vitis vinefera L. Var. sahibi and hussaini. Results: Macro and microscopic characters of Vitis vinefera L. seeds Var. sahibi and hussaini were analyzed. Physicochemical parameters such as foreign matter, extractive values, ash content, $\mathrm{pH}$ and fluorescent behaviour of seed powder were done by using WHO recommended parameters. A preliminary phytochemical screening was done and revealed
\end{abstract}

the presence of different phytoconstituents like carbohydrates, flavonoids, glycosides, tannins, sterols and fixed oil. Conclusion: This is the first report of its kind on the pharmacognostic studies of Vitis vinefera $\mathrm{L}$. seeds Var. sahibi and hussaini and will serve as valuable source of information towards establishing pharmacognostic standards on identification, purity, quality and classification.

Key words: Grapes, Hussaini, Macroscopy, Microscopy, Physicochemical, Sahibi.

Corresponding author: Zulfiqar Ali Bhat, Department of Pharmaceutical Sciences, University of Kashmir, Srinagar-190006, Jammu and Kashmir, INDIA.

Phone: 9419077701

Email: zabhat2000@gmail.com

DOI : 10.5530/pj.2016.5.9

\section{INTRODUCTION}

Grapes (Vitis vinifera L.), are one of the world's largest fruit crop, with a total production of approximately 75.1 million tons in 2013. Although, a high part of grapes is made into wine, another part is dried into raisins, a considerable part is consumed as table grapes. Vitis vinifera L. contains large amounts of phytochemicals such as phenolic compounds which offer health benefits via their vital antioxidant activity to neutralize free radicals in biological systems. Grape seeds and skins which are a low-value by-products of wine making or juice making operations are considered to be economical and a good source of these high-quality phenolic compounds. ${ }^{1}$ The polyphenol compounds are as much as $60-70 \%$ in grape seeds compared only $10 \%$ in the fruit and $28-35 \%$ in the peels; ${ }^{2}$ these levels are influenced by the grape variety and ecological factors. ${ }^{1}$ Most of the polyphenol compounds found in grape seeds are monomerics catechin, epicatechin and gallic acid, and the polymeric and oligomeric procyanidins. ${ }^{3}$ These compounds are of interest in pharmaceutical and food industries for therapeutic treatments and health supplements. ${ }^{2}$ The medicinal and nutritional importance of Vitis vinifera L. has been heralded for thousands of years. Egyptians consumed this fruit at least 6000 years ago, and a number of ancient Greek philosophers praised the healing power of grapes-usually in the form of wine. European folk healers developed an ointment from the sap of grapevines to cure skin and eye diseases. Unripe grapes were used to treat sore throats and dried grapes (raisins) were used to cure constipation and thirst. The ripe, sweet grapes were used to treat a range of health problems including cancer, cholera, smallpox, nausea, eye infections, and skin, kidney, and liver diseases. Moreover, grapes are helpful in bilious dyspepsia, dysuria, haemorrhage, in chronic bronchitis, gout and heart diseases. ${ }^{4,5}$

The World Health Organisation (WHO) has described guiding principles for the standardisation of medicinal plants with regard to their macroscopic and microscopic description. Several studies have recommended that the pharmacognostic particulars of a plant may provide useful criteria in identification and authentication of plant drugs. ${ }^{6}$ In view of the importance of Vitis vinefera L. seeds in conventional and contemporary system of medicine, it was thought worthwhile to develop quality standard for the same. As far as botany and chemistry of this plant is concerned, large number of scientific data is accessible but a systematic standardization study is still missing. Hence, in the present investigation an attempt has been made to standardize the Vitis vinefera L. seeds (Var. sahibi \& hussaini) ${ }^{7}$ using microscopic characters, physicochemical values and heavy metal analysis.

\section{MATERIAL AND METHODS}

\section{Collection and identification of plant material}

Seeds of Vitis vinefera L. Var. sahibi \& hussaini were collected from Rapora Lar, District Ganderbal, J\&K, India and authenticated by Akhtar H. Malik, Curator, Center for Biodiversity \& Taxonomy (CBT), University of Kashmir, J\&K, India under voucher specimen No. 2352-(KASH) Herbarium/CBT/KU/15 for Sahibi variety and No. 2353-(KASH) Herbarium/CBT/KU/15 for Hussaini variety. The grape seed varieties has been retained in Pharmacognosy Research Laboratory in the Department of Pharmaceutical Sciences and also deposited in the herbarium of the Botany department, University of Kashmir for future reference.

\section{Macroscopic and microscopic analysis}

Macroscopic characters of the seeds were studied according to the method of Evans. It refers to evaluation by means of organs of sense and helps to judge various parameters viz. appearance, odour, taste and colour. ${ }^{8}$ On the other hand microscopic examination of the seeds are not only essential to identify the adulterants but also indispensable in the correct identification of the plant. ${ }^{9}$ For microscopic studies of the grape seeds, the procedure recommended by Johansen was followed. ${ }^{10}$ 


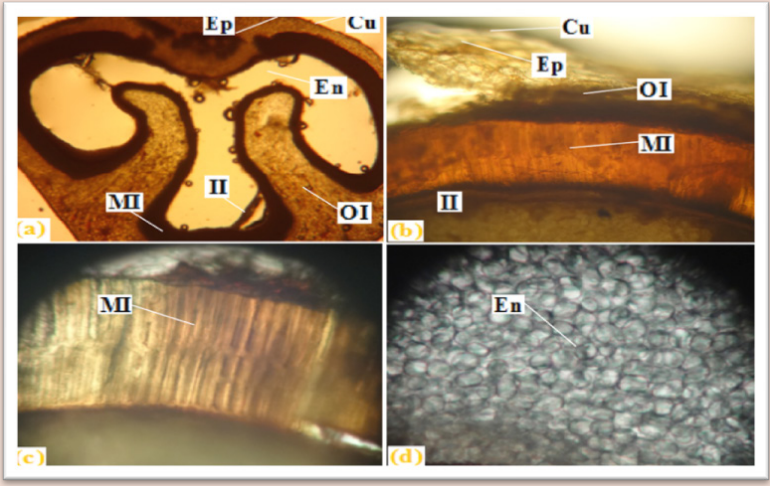

Figure 1: a) Transverse section of Vitis Vinefera L. seeds Var. sahibi entire view. b) T.S. of seed showing regions of cuticle, epidermis, outer integument, medium integument \& inner integument. c) T. S. of seed showing medium integument. d) T. S. of seed showing endosperm. Cu - Cuticle; Ep - Epidermis; Ol - Outer integument; II - Inter integument; MI - Medium integument; En - Endosperm.
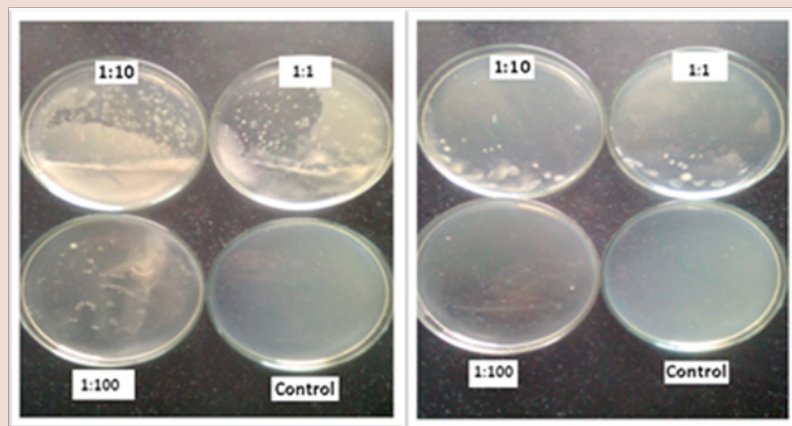

Figure 3: Plates showing microbial growth (a) Vitis vinifera L. Var. sahibi (b) Vitis vinefera L. Var. hussaini.

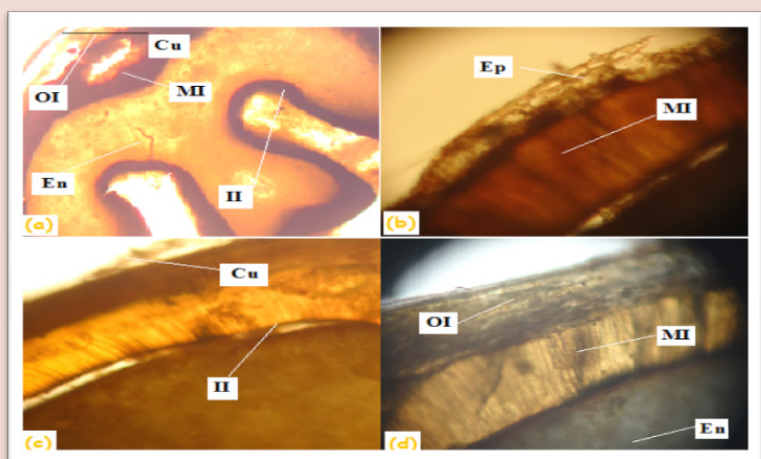

Figure 2: a) Transverse section of Vitis vinefera L. seeds Var. hussaini entire view. b) T.S. of seed showing regions of epidermis \& medium integument. c) T. S. of seed showing cuticle \& inner integument. d) T. S. of seed showing outer integument, medium integument \& endosperm. Cu - Cuticle; Ep - Epidermis; Ol - Outer integument; II - Inter integument; En - Endosperm.

\section{Physicochemical analysis}

The grape seeds were shade dried and powdered using mechanical grinder for determination of physicochemical parameters such as total ash value, water soluble ash value, acid insoluble ash value, foreign organic matter, loss on drying, foaming index, swelling factor, ${ }^{11}$ determination of resin and fat content, ${ }^{12}$ water soluble extractives and alcohol soluble extractives, ${ }^{11,13} \mathrm{pH}$ determination. ${ }^{14}$ Fluorescence analysis study of powdered drug material with different reagents was carried out to observe the color reactions. The drug was treated with various chemical reagents and exposed to visible and ultraviolet light to study their fluorescence behaviour. ${ }^{15}$ The presence of heavy metals analysis was carried out quantitatively by Atomic absorption spectrophotometer. ${ }^{16}$ Qualitative phytochemical screening was carried out on the grape seed extracts (petroleum ether, chloroform, ethyl acetate, methanol, aqueous) to determine the presence of carbohydrates, flavonoids, phenolic compounds, glycosides, alkaloids, proteins and amino acids, saponins, sterols, mucilage, resins, lipids/fats etc. by following standard procedures. ${ }^{17,18}$

\section{RESULT}

The standardization of a crude drug is an integral part of establishing its correct identity. Before any crude drug can be included in a herbal
Table 1: Physicochemical analysis of Vitis vinefera L. seeds (Var. sahibi \& hussaini)

\begin{tabular}{ccc}
\multirow{2}{*}{ Physico-chemical Parameters } & \multicolumn{2}{c}{ Results } \\
\cline { 2 - 3 } & Var. sahibi & Var. hussaini \\
\hline Total ash value (\% w/w) & 2.33 & 2.65 \\
Acid insoluble ash value (\% w/w) & 0.27 & 0.24 \\
Water soluble ash value (\% w/w) & 1.28 & 1.1 \\
Swelling index (\% w/v) & 2.9 & 2.6 \\
Resin content (\% w/w) & 6.34 & 14.6 \\
Fat content $(\% \mathrm{w} / \mathrm{w})$ & 10 & 10 \\
Foreign matter $(\% \mathrm{w} / \mathrm{w})$ & 2.02 & 3.02 \\
Loss on drying $(\% \mathrm{w} / \mathrm{w})$ & 13.75 & 12.35 \\
Foaming index & Less than 100 & Less than 100 \\
pH 1\% solution & 5.36 & 5.87 \\
pH 10\% solution & 4.39 & 5.12 \\
\hline
\end{tabular}

pharmacopoeia, pharmacognostic parameters and standards must be established.

\section{Macroscopical characters}

The two varieties of Vitis vinefera L.: sahibi and hussaini differ only in their size. In Sahibi variety, the shape of the seed was pear shaped, the colour of seed was dark brown, the surface is smooth with ridge on back surface, apex is discoidal, size is $4-8 \mathrm{~mm}$ long, taste is bitter. In hussaini variety, the shape of the seed was also pear shaped, the colour of seed was dark brown, the surface is smooth with ridge on back surface, apex is discoidal, size is 4-6 mm long, taste is bitter.

\section{Microscopic analysis}

The transverse section of the seeds of both the varieties has been found to be almost same and revealed five zones (Figure $1 \& 2$ ): cuticle and epidermis; outer integument or soft seed coat, composed of large parenchymatous cells; medium integument or hard seed coat, composed of two layers of cells; inner integument; (v) endosperm and embryo. At the first observation, the cuticle was found thin and, the epidermis was constituted of rectangular cells. The outer integument was constituted of parenchymatous cells. The epidermis and the outer integument were made of a soft layer of cells, which covered the seed. The raphe was 
Table 2: Extractive values of Vitis vinefera L. seeds (Var. sahibi \& hussaini)

\begin{tabular}{ccccc}
\hline & \multicolumn{2}{c}{$\begin{array}{c}\text { Vitis vinifera } \mathrm{L} \\
\text { (Var. sahibi) }\end{array}$} & $\begin{array}{c}\text { Vitis vinefera } \mathrm{L} . \\
\text { (Var. hussaini) }\end{array}$ \\
\cline { 2 - 5 } Extracts & $\begin{array}{c}\text { Cold extraction } \\
(\% \mathrm{w} / \mathrm{w})\end{array}$ & $\begin{array}{c}\text { Successive } \\
\text { extraction } \\
(\% \mathrm{w} / \mathrm{w})\end{array}$ & $\begin{array}{c}\text { Cold extraction } \\
(\% \mathrm{w} / \mathrm{w})\end{array}$ & $\begin{array}{c}\text { Successive extraction } \\
(\% \mathrm{w} / \mathrm{w})\end{array}$ \\
\hline Petroleum ether extract & 10.95 & 15.39 & 7.75 & 10.42 \\
Chloroform extract & 11.85 & 2.6 & 10.97 & 6.74 \\
Ethyl acetate extract & 9.65 & 1.78 & 10.97 & 3.22 \\
Methanol extract & 12.85 & 9.04 & 12.02 & 6.22 \\
Aqueous extract & 7.75 & 1.62 & 16.37 & 2.18 \\
\hline
\end{tabular}

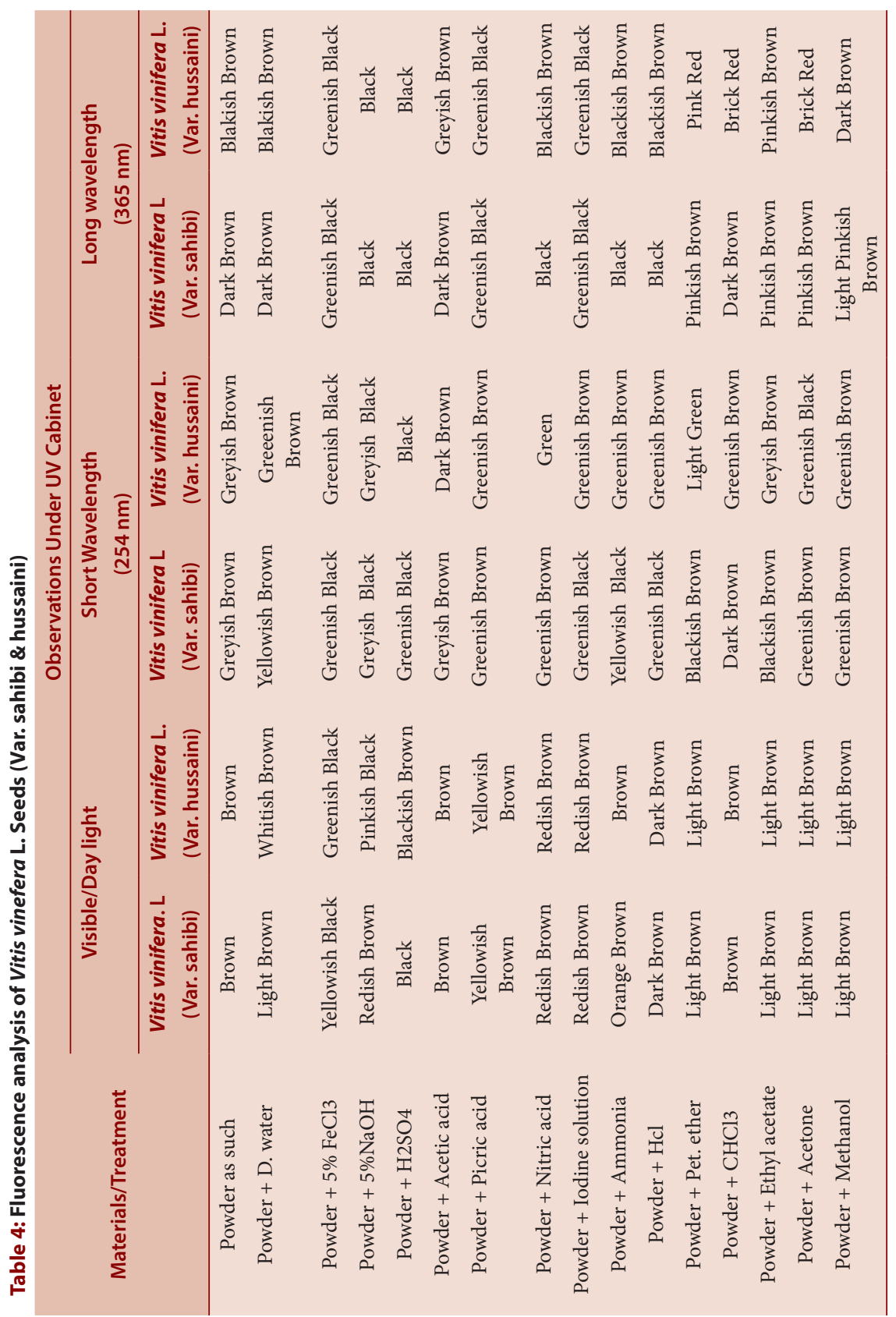




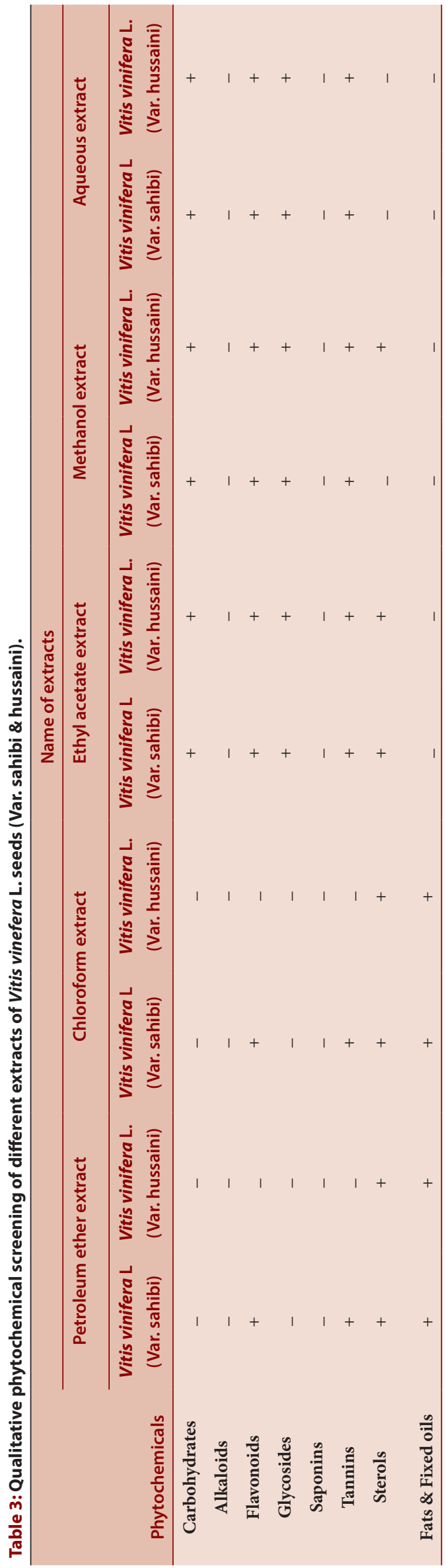

located in the dorsal face of this tissue. Two layers of rectangular cells with thin walls constituted the medium tissue or medium integument. The inner integument is between the medium integument and the endosperm. The centre of the seed was occupied by parenchymatous tissue, surrounded by integuments and containing the embryo sac.

\section{Physicochemical analysis}

Various physicochemical parameters of Vitis vinefera L. seeds (Var. sahibi and hussaini) like loss on drying, total ash value, water soluble ash, acid insoluble ash, swelling index, resin content, fat content, foreign content, loss on drying, foaming index and $\mathrm{pH}$ values were determined and are shown in Table 1.

\section{Extractive values}

Extracts were prepared with various solvents. Percentages of the extractive values were calculated with reference to air dried drug and are given in Table 2.

\section{Phytochemical analysis}

The results of qualitative phytochemical analysis of the different seed extracts of the Vitis vinefera L. (Var. sahibi and hussaini) are shown in Table 3. Preliminary phytochemical analysis revealed the presence of medicinally important secondary metabolites like flavonoids, glycosides, tannins and sterols, whereas alkaloids and saponins were absent.

\section{Fluorescence analysis of extracts}

Fluorescence study of Vitis vinefera L. seeds (Var. sahibi and hussaini) were performed as per standard procedure. Powdered seeds were treated with various chemical reagents and exposed to visible and ultraviolet light (254 and $365 \mathrm{~nm}$ wavelengths) to study their fluorescence behaviour. The characteristic fluorescence colours of the powdered seeds with various chemical reagents are stated in Table 4.

\section{TLC analysis}

The TLC of Ethyl acetate extract of the two varieties of Vitis vinefera L. seeds on Silica gel 60 F254 pre-coated sheets using different solvent systems showed highest number of spots in Chloroform : Ethyl acetate: Methanol : Formic acid (6:2:1:0.5). Methanolic extract of these two varieties showed highest number of spots in Chloroform : Ethyl acetate: Formic acid (10:8:2) using Iodine vapour as viewing medium (Table 5).

\section{Microbial load and Heavy metal analysis}

At the stock dilutions of 1:1,1:10 and 1:100, the number of microbial colonies which were visible to the naked eye were 131,81 and 51 for sahibi variety and 24, 15 an 6 for hussaini variety respectively. All these microbial colonies were round in shape and white in colour in both sahibi and hussaini varities (Figure 3). Heavy metal analysis results of both these varieties showed that the Cadmium, Lead and Cobalt were not detected which indicates that it is safe for human consumption.

\section{DISCUSSION}

The source and quality of raw materials play a pivotal role in guaranteeing the quality and stability of herbal preparations. Many factors can affect the quality and consequently the therapeutic value of herbal medicines, such as light exposure, temperature, water availability, nutrients, period and time of collection, method of collecting, drying, packing, storage and transportation of raw material, age and part of the plant collected. ${ }^{19}$ For this reason it is of utmost importance to have raw materials with a consistent and reproducible quality standard. Pharmacognostic standardization including physico-chemical parameters are the primordial steps meant for identification, authentication, and detection of adulteration and also compilation of quality control of crude drugs. In this regard, the microscopic and macroscopic features of Vitis vinefera $\mathrm{L}$. 
Nowshehri et al.: Pharmacognostical evaluation of Grape seeds

Table 5: Thin layer chromatography pattern of ethyl acetate and methanolic extracts of Vitis vinifera L. seeds (Var. sahibi \& hussaini)

\begin{tabular}{|c|c|c|c|c|}
\hline Sample extracts & Solvent systems & Detection of spots & No. of spots & Rf values \\
\hline \multirow{3}{*}{$\begin{array}{l}\text { Ethyl acetate extract } \\
\text { (Sahibi) }\end{array}$} & HE:EA (1:05) & Iodination & 4 & $0.08,0.3,0.8,0.91$ \\
\hline & $\begin{array}{c}\mathrm{CH}: \mathrm{EA}: \mathrm{ME}: \mathrm{FA} \\
(6: 2: 0.5: 1)\end{array}$ & Iodination & 6 & $0.2,0.33,0.5,0.61,0.76,0.98$ \\
\hline & $\begin{array}{c}\text { CH:EA:ME:FA } \\
(6: 2: 1: 0.5)\end{array}$ & Iodination & 6 & $0.10,0.28,0.42,0.53,0.79,0.95$ \\
\hline \multirow[t]{3}{*}{$\begin{array}{c}\text { Ethyl acetate extract } \\
\text { (Hussaini) }\end{array}$} & $\begin{array}{c}\text { PE:EA:ME } \\
(17: 2: 1)\end{array}$ & Iodination & 5 & $0.16,0.27,0.62,0.72,0.95$ \\
\hline & $\begin{array}{c}\text { CH:EA:ME:FA } \\
(6: 2: 0.5: 1)\end{array}$ & Iodination & 5 & $0.24,0.40,0.51,0.66,0.93$ \\
\hline & $\begin{array}{c}\text { CH:EA:ME:FA } \\
(6: 2: 1: 0.5)\end{array}$ & Iodination & 6 & $0.07,0.26,0.39,0.48,0.71,0.93$ \\
\hline $\begin{array}{c}\text { Methanolic extract } \\
\text { (Sahibi) }\end{array}$ & $\begin{array}{c}\text { CH:EA:FA } \\
(10: 8: 2)\end{array}$ & Iodination & 5 & $0.16,0.38,0.56,0.70,0.96$ \\
\hline $\begin{array}{c}\text { Methanolic extract } \\
\text { (Hussaini) }\end{array}$ & $\begin{array}{c}\text { CH:EA:FA } \\
(10: 8: 2)\end{array}$ & Iodination & 3 & $0.16,0.48,0.58$ \\
\hline
\end{tabular}

Hexane $=\mathrm{HE}$; Ethyl acetate $=\mathrm{EA}$; Chloroform $=\mathrm{CH}$; Methanol=ME; Formic acid $=\mathrm{FA}$

Petroleum ether=PE.

seeds (Var. sahibi and hussaini) have been studied. The extractive values give an idea about the chemical constitution of the drug and from the study, the extractive value of methanol was found to be highest followed by chloroform in case of sahibi variety and aqueous followed by methanol in case of hussaini variety. The ash value determines the earthy matter or inorganic composition and other impurities present along with the drug. The analysis of ash values indicates that foreign inorganic matter in considerably normal amounts in both the varieties. Heavy metal analysis and microbial load for the drug was in normal values as set down by WHO. When physical and chemical methods are inadequate, the plant material may be identified from their adulterants on the basis of fluorescence characteristics. The fluorescent analysis under visible light and UV light by treatment of different chemical reagents showed different colour. This is attributed to the ultra violet light which produces fluorescence in many natural products that do not visibly fluoresce in daylight. Thus fluorescence is used for qualitative assessment of crude drug. ${ }^{20}$ Behaviours of the powdered drug with different chemical reagents and preliminary phytochemical analysis are helpful for detection of various phytoconstituents.

\section{CONCLUSION}

In conclusion, these pharmacognostic standards for the seeds of Vitis vinefera L. (Var. sahibi and hussaini) are laid down for the first time in this study. These would not only help in setting indices for identification of raw material and preparation of plant monograph but also will serve as a diagnostic tool in development of pharmacopoeial standards for the future studies.

\section{REFERENCES}

1. Sonia MA, Lila BM, Yves C, Lamia MH, Farid D, Aida M, et al. Optimization of the recovery of phenolic compounds from Algerian grape by-products. Industrial Crops and Products. 2015;77:123-32

2. Vayupharp B and Laksanalamai V. Recovery of Antioxidants from Grape Seeds and its Application in Fried Food. J Food Process Technol. 2012;3(4):152.

3. Adámez JD, Samino EG, Sánchez EV, González-Gómez D. In vitro estimation of the antibacterial activity and antioxidant capacity of aqueous extracts from grape-seeds (Vitis vinifera L.). Food Control. 2012:24(1):136-41.

4. Kar P, Laight D, Shaw KM, Cummings MH. Flavonoid-rich grapeseed extracts: a new approach in high cardiovascular risk patients? Int J Clin Pract. 2006 60(11):1484-92.

5. El-Hawary S, El-Fouly k, El Gohary HM, Meselhy KM, Slem A and Talaat Z Phytochemical and biological investigation of Vitis vinifera L. (Flame cultivar), Family Vitaceae cultivated in Egypt. Nat Sci. 2012;10(10):48-59.

6. Bhatti R, Singh J, Saxena AK, Suri N and Ishar MPS. Pharmacognostic Standardisation and Antiproliferative Activity of Aegle marmelos (L.) Correa Leaves in Various Human Cancer Cell Lines. Indian J Pharm Sci. 2013;75(6):628-34.

7. Rather $\mathrm{AQ}$. Management of phytophagous and predatory mites in vineyards of Jammu and Kashmir, India. Acta Hortic. 2008;785:327-34.

8. Evans WC, Evans D, Trease GE. Trease and Evan's pharmacognosy. $16^{\text {th }}$ ed. Saunders/Elsevier; 2009.

9. Trease GE, Evans WC. Pharmacognosy. International edition. W.B.Saunders. 2008;2(3):538-44.

10. Johansen DA. Plant Microtechnique. New York: McGraw-Hill 1940;423

11. Chauhan G, Sharma M, Kharkwal H, Varma A. Pharmacognostic, preliminary phytochemical studies and anticancerous potential of Trigonella foenum-graecum. Pharma Sci monitor. 2011;2(2):72-81.

12. Mukherjee PK. Quality Control of Herbal Drugs. 1st ed. New Delhi: Business Horizons. 2002;9-564

13. Government of India. Indian Pharmacoepeia. New Delhi: Ministry of Health and Family Welfare, Controller of Publication. 1996;A-53.

14. Anonymous. Standardization of Single Unani Medicine. Part-I, II. New Delhi: Central Council for Research in Unani Medicine (CCRUM) 1987.

15. Menpara D and Chanda S. Phytochemical and pharmacognostic evaluation of leaves of Pongamia pinnata L. (Fabaceae). Pharmacognosy Communications. 2014;4(2):3.

16. Anonymous: Pharmacopoeia of India. Govt. of India, Ministry of Health, Controller of publication, New Delhi 1996.

17. Khandelwal KR. Practical Pharmacognosy, Techniques and Experiments. $13^{\text {th }}$ ed. Pune, India: Nirali Prakashan. 2005;18-153

18. Chulet R, Joseph L, George M, Pradhan P. Pharmacognostic standardization and phytochemical screening of Albizzia lebbeck. J Chem Pharm Res. 2010; 2(1):432-43

19. Calixto JB. Efficacy, safety, quality control, marketing and regulatory guidelines for herbal medicines (phytotherapeutic agents). Brazilian Journal of Medical and Biological Research. 2000;33(2):179-89.

20. Menpara D, \& Chanda S. Phytochemical and pharmacognostic evaluation of leaves of Pongamia pinnata L. (Fabaceae). Pharmacognosy Communications. 2014;4(2):3 
PICTORIAL ABSTRACT

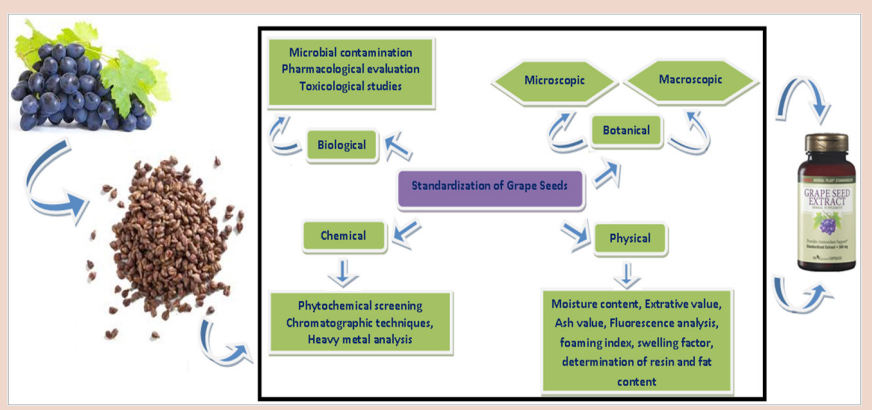

\section{SUMMARY}

- Grapes (Vitis vinifera L.), are one of the world's largest fruit crop, with a total production of approximately 75.1 million tons in 2013.

- Grape seeds and skins are considered to be economical and a good source of high-quality phenolic compounds.

- In view of the importance of Vitis vinefera L. seeds in conventional and contemporary system of medicine, it was thought worth while to develop quality standard for the same.

- This is the first report of its kind on the pharmacognostic studies of $\mathrm{Vi}$ tis vinefera L. seeds Var. sahibi and hussaini and will serve as valuable source of information towards establishing pharmacognostic standards on identification, purity, quality and classification.

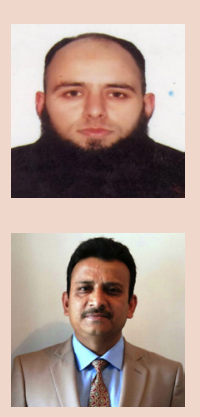

\section{ABOUT AUTHORS}

Javaid Ashraf Nowshehri: Is research scholar in the Department of Pharmaceutical Sciences, University of Kashmir, Srinagar, Jammu \& Kashmir. He has published several research papers. Currently he is working on medicinal plants with special emphasis on Grape seeds of Kashmir valley. His research focused on the Pharmacognostic and Pharmacological studies on Grape seeds. His area of study is pharmacognosy, photochemistry \& pharmacology.

Prof. Zulfiqar Ali Bhat: Is presently heading Department of Pharmaceutical Sciences, University of Kashmir. His area of specialization is Pharmacognosy \& Phytochemistry. He has more than 20 years of teaching \& 15 years of research experience. His area of research is mainly focused on medicinal plants of Kashmir Valley and Ladakh region. He has worked on plants having CNS, antidiabetic, anti-inflammatory, antiulcer, antihyperlipidemic \& hepatoprotective activity. Pharmacognostic, phytochemical and pharmacological evaluation of plant extracts and isolated compounds are some priorty areas of his research. He is also Deputy Co-ordinator of UGC SAP programme, University of Kashmir. He is also member of many scientific journals. Prof. Bhat has number of national and international publications to his credit and has guided a number of Ph.D scholars. He also has a number of projects to his credit.

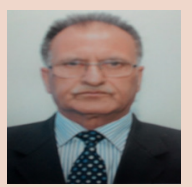

Prof. M.Y. Shah: Is presently Dean Unani Medicine \& Rector, Leh/Kargil Satellite Campuses of the University of Kashmir. Prof. M.Y. Shah has been appointed as UGC nominee by UGC on the governing body of Utrtrakhand Technical University, Dehradun. He has been appointed as member Expert Committee for allotment of funds under Innovative Programme in the field of Technology \& Engineering (PHARMACY) and also has been appointed as member Expert Committee for screening/ short listing of Major/Minor Research Projects in the Field of PHARMACY. He has guided many Ph. D scholars and has more than 80 national \& international publications to his credit. 